order $p_{1}^{a_{1}} p_{2}^{a_{2}}$ could, in view of Burnside's results, * have been made much more general.

This enumeration of a few points in which we think the book might be improved should not be understood as detracting from our statement at the beginning of this review commending the book. In publishing so excellent a treatment of the subject Professor Netto has performed a service of value to the mathematical public.

W. B. Fite.

Einführung in die höhere Mathematik. Von Emanuel Czuber. Teubner, 1909. $382 \mathrm{pp}$.

THIs book is an amplification of the lectures on differential and integral calculus given by Professor Czuber at the technical school in Vienna. The treatment has been extended so as to form a good introduction to higher mathematics, adapted for students other than technical students. The subjects are developed with much care and rigor.

There are essentially three divisions, viz., Functions of real variables, Algebra, and Analytical geometry. The opening chapter is on real and imaginary numbers. The number concept is developed for use in the functions of a real variable. The second chapter is a short, concise, and elegant presentation of infinite series and products. Besides simple demonstrations the subject is made easier for the student by the many wellchosen examples to illustrate the points in question.

Chapters III and IV begin the theory of functions of real variables. The general idea of a function, limit of a function, and continuity are the principal topics discussed. Here again we find many well-chosen examples. The function

$$
f(x)=\lim _{n=\infty} \frac{n x+2}{n x^{2}+1}
$$

is given to show the difference between the value of a function given by direct substitution and that obtained by the limiting process. The substitution of $x=0$ gives $f(0)=2$, while if we first proceed to the limit and then put $x=0$ we have $f(0)= \pm \infty$.

The example

$$
f(x)=\frac{x}{1+e^{1 / x}}
$$

is a good illustration of a function which is continuons for $x=0$, but whose derivative is discontinuous at this point.

* Proceedings Lond. Math. Society, series 2, vol. 1 (1904), p. 388. 
$f(x)=x[x],([x]$ indicating the largest integer contained in $x$ ), is an example of a function which is discontinuous at points for which $x$ is an integer, but whose derivative is continuous. $f(x)=x[1 / x]$ is an example of a function which is discontinuous at points where $x$ is an integer and whose derivative is also discontinuous at these points.

The chapter on the applications of the differential calculus contains nothing more than the applications to indeterminate forms and maxima and minima. It seems rather unfortunate that Taylor's and Maclaurin's series should be omitted entirely.

The part of the book dealing with algebra contains a chapter of forty pages on determinants, and a chapter on algebraic equations which treats of resultants, discriminants, and the solution and discussion of numerical equations.

The last 140 pages are devoted to analytical geometry. It is rather remarkable to note that geometric loci are discussed on the fourth page, the equations of the conics, strophoid, cissoid, Cassinian ovals, and four cusped hypocycloid being derived as examples in loci. The particular equations of the line and conic are then taken up and discussed in detail. The treatment of analytical geometry is satisfactory indeed.

The book as a whole is well adapted to the purpose for which it was written, but as is usually the case with the European text it does not contain a sufficient number of exercises and problems which are left for the student. Throughout there are many footnotes, mostly of a historical nature, which are sufficient to arouse an interest in the history of the subject.

$$
\text { C. L. E. Moore. }
$$

\section{Récréations Mathématiques et Problèmes des Temps Anciens et}

Modernes. Par W. W. Rouse Ball. Deuxième édition française traduite d'après la quatrième édition anglaise et enrichie de nombreuses additions par J. Fitz-Patrick. Paris, A. Hermann, 1907. 8 vo. 3 parts. 5 francs each.

THE subject of mathematical recreations has always occupied a prominent position in the history of science. Zeno, Alcuin, Bachet, Fermat, Lucas, - these are only a few of the hundreds of names that might be mentioned of those who have contributed to this interesting field. Many of these men have been mathematicians of no small repute, for in reality the border line between recreative and serious mathematics is purely imaginary. To the mathematician all mathematics is a recreation; it is to 